\title{
Parasitoses Intestinais nos Índios Xavánte de Parabubure, Mato Grosso, Brasil'
}

Em agosto de 1993, foram analisadas 82 amostras de fezes coletadas entre as populações Xavante das aldeias Estrêla a Etepo' ori $(n=209)$, da Área Indígena Parabubure $\left(53^{\circ} \mathrm{W}, 14^{\circ} \mathrm{S}\right)$, Estado de Mato Grosso. Seis meses antes da realização deste inquérito, a população dessas aldeias havia sido tratada em massa com mebendazole. No campo, as amostras foram preservadas em MIF e posteriormente processadas pelo método de sedimentação (Lutz, 1919). Os resultados obtidos foram: Ascaris lumbricoides (28,4\%), Ancilostomideos (13,6\%), Strongyloides stercoralis (9,9\%), Giardia lamblia (8,6\%), Entamoeba histolytica (3,7\%), Entamoeba coli $(54,3 \%)$, Endolimax nana $(4,9 \%)$ e lodamoeba bütschllii $(23,5 \%)$. Não foram detectadas associações estatisticamente significantes entre sexo e positividade para helmintos e protozoários. No caso das helmintoses, as prevalências mais elevadas foram observadas no grupo de 0 a 10 anos de idade, que respondem por $57 \%$ da prevalência total. Em relação ao poliparasitismo por helmintos, 37,8\% dos indivíduos apresentaram-se parasitados apenas por uma espécie e 7,3\% por duas. Os resultados obtidos estão próximos aos encontrados por Santos et al. (1995) entre os Xavánte da Area Indígena de Pimentel Barbosa. Em ambas as áreas a população Xavánte tende a sedentarizar-se mantendo suas aldeias no mesmo local por mais de duas décadas. A ausência de uma infraestrutura sanitária mínima - tanto nas aldeias como nos postos indígenas - e a sedentarização, favorecem a contaminação do solo e dos córregos próximos às aldeias por formas infectantes de helmintos e protozoários.

\footnotetext{
${ }^{1}$ Estudo realizado como parte do projeto: Medicina
Tradicional e Saúde da Comunidade: Pesquisa -
Ação com Mulheres Xavánte, financiado pelo
Fundo de Amparo à Pesquisa do Estado de São

${ }^{1}$ Estudo realizado como parte do projeto: Medicina
Tradicional e Saúde da Comunidade: Pesquisa-
Ação com Mulheres Xavánte, financiado pelo
Fundo de Amparo à Pesquisa do Estado de São

${ }^{1}$ Estudo realizado como parte do projeto: Medicina
Tradicional e Saúde da Comunidade: Pesquisa-
Ação com Mulheres Xavánte, financiado pelo
Fundo de Amparo à Pesquisa do Estado de São

${ }^{1}$ Estudo realizado como parte do projeto: Medicina
Tradicional e Saúde da Comunidade: Pesquisa-
Ação com Mulheres Xavánte, financiado pelo
Fundo de Amparo à Pesquisa do Estado de São Paulo.
}

\section{REFERÊNCIAS BIBLIOGRÁFICAS}

LUTZ, A., 1919. O Schistosoma mansoni e a schistosomatose segundo observações feitas no Brasil. Memórias do Instituto Oswaldo Cruz, 11: 121-155.

SANTOS, R. V.; COIMBRA Jr. \& SILVA, J. P., 1995. Intestinal parasitism in the Xavánte Indians, Central Brazil. Revista do Instituto de Medicina Tropical de São Paulo, 37: 145-148. São Paulo.

$\begin{array}{r}\text { Rubens V. Ianelli } \\ \text { Joaquim P. Silva }\end{array}$
Escola Nacional de Saúde Pública/Fiocruz
Rua Leopoldo Bulhões, 1480
Rio de Janeiro, RJ, 21041-210, Brasil
Sandra M Agostini
Fundação Nacional do Índio
Rua Ministro João Alberto, 179

Rubens V. lanelli 